\title{
NEGOCIOS DIECIOCHISTAS EN TORNO A LA RESTAURACIÓN DEL ANTIGUO OBISPADO ASIDONENSE
}

\section{CARlos L. LADERo Fernández \\ UNIVERSIDAD DE SEVILLA}

\begin{abstract}
RESUMEN: El siguiente trabajo trata una de las etapas fundamentales de la historia de la restauración del obispado asidonense: el siglo XVIII. Centuria ilustrada de importantes cambios, la ciudad e iglesia de Jerez aprovecharon la coyuntura histórica para reivindicar la antigua sede visigótica y separarse de la sede hispalense. La documentación del Archivo Catedral de Sevilla permite adentrarnos en el pleito que sostuvieron y contrastar la información original con la bibliografía actual.
\end{abstract}

PALABRAS CLAVE: Obispado asidonense; Jerez de la Frontera; arzobispado de Sevilla; obispado de Cádiz; siglo XVIII.

\section{BUSINESS IN XVIII CENTURY ABOUT THE RESTORATION OF THE ANCIENT DIOCESE OF ASIDONIA}

\begin{abstract}
This essay deals with one of the most important period in the history of the restoration of the diocese of Asidonia: the Eighteen century. Century full of important changes, the city and church of Jerez took advantage of the economical situation to ask the old ancient Visigoth diocese and to separate from the Archdiocese of Seville. The Archive of the Cathedral of Seville' documentations allows to know the lawsuit which they had and contrast the original information with the current bibliography.
\end{abstract}

KEY WORDS: Diocese of Asidonia; Jerez de la Frontera; Archdiocese of Seville; Diocese of Cádiz; XVIII Century.

Recibido: 20-09-2014/Aceptado: 02-12-2014 


\section{INTRODUCCIÓN}

El 3 de marzo de 1980, el papa Juan Pablo II decretaba la erección del obispado de Asidonia-Jerez. Tras siglos de reclamaciones, los cabildos jerezanos ganaron el pulso a la archidiócesis de Sevilla cuyos límites se ajustaron a los términos geográficos actuales. ${ }^{1}$ Se cerraba así una etapa de diferencias y pleitos de varios siglos que tuvo en la Edad Moderna uno de sus momentos cruciales debido, en parte, a la creación y reorganización de varias iglesias españolas y al interés de ciertos sujetos por prestigiar a la ciudad de Jerez y administrar sus importantes rentas eclesiásticas. En este estudio, nos acercaremos a los intentos del siglo XVIII sin olvidar la trayectoria de la iglesia xericense desde la reconquista e incluso antes, enlazando con el obispado asidonense cuya restauración se reclamaba. Podremos, por tanto, apreciar y contrastar los argumentos que sobre la rehabilitación esgrimieron los jerezanos y las defensas de las iglesias de Sevilla y Cádiz que consideraban trasladado el antiguo obispado visigótico a esta última, pretendiendo abortar los intentos de Jerez la primera y ganar cuotas de poder la segunda. Nosotros, siguiendo el criterio de Vega y García ${ }^{2}$ o de López Fernández ${ }^{3}$, hemos apostado por el vocablo restauración pues, como señalan, el obispado de Asidonia permaneció in partibus infidelium en el anuario pontificio hasta la década de los ochenta del siglo XX. En definitiva, en este trabajo se observan las condiciones necesarias para la constitución de un obispado en las postrimerías del Antiguo Régimen y se repasa la situación espiritual y material de la iglesia de Jerez en dicho momento en oposición a otras diócesis españolas. Para ello, hemos recurrido al fondo documental del Archivo Catedral de Sevilla y a la bibliografía, imprescindible para que los datos originales tomen valor. El método seguido detalla, en primer lugar, el curso legal de la reivindicación jerezana en el siglo XVIII deteniéndose luego en su defensa, donde pretende incorporarse sin éxito el obispado de Cádiz, y en los requisitos demandados por Roma para la constitución/restauración de una diócesis que son refutados por la sede hispalense. Por tanto, salvando la orientación que damos en el primer epígrafe, obviamos el seguimiento cronológico que puede resultar confuso y demasiado prolijo.

\footnotetext{
1 GARCÍA ROMERO, Francisco Antonio y VEGA GEÁN, Eugenio José: "Preparando una nueva diócesis", XX Siglos, volumen 16, nº 54, 2005, p. 48.

2 GARCÍA ROMERO, Francisco Antonio y VEGA GEÁN, Eugenio José: "La larga marcha hacia el obispado", XX Siglos, volumen 16, n 54, 2005, p. 40.

3 LÓPEZ FERNÁNDEZ, Antonio: "La diócesis de Jerez" en J. Sánchez Herrero, Historia de las diócesis españolas: Sevilla, Huelva, Jerez, Cádizy Ceuta, Madrid/Córdoba, BAC, 2002, p. 576.
} 


\section{LA REIVINDICACIÓN DE JEREZ Y SU CURSO LEGAL EN EL SIGLO XVIII}

La reivindicación más antigua de los jerezanos en el Setecientos viene de la mano del capitular Antonio de Mesa Xinete que en 1762 publicó una pequeña obra con la pretensión de identificar a Jerez con la Asido visigótica y, por consiguiente, con su obispado. Este jurista, estudiado por Repetto Betes, hizo todo lo posible por acercar al lector a su tesis hasta el punto que su demostración histórica de 1766 "no ha merecido el aplauso de la crítica". Amigo del padre Flórez, quien acabó compartiendo su exposición y alabando su análisis, Mesa fue una personalidad de su momento: creó el beaterio de las Nazarenas de Jesús para prostitutas arrepentidas en $1749^{5}$, impulsó en el mismo año una casa para niñas huérfanas ${ }^{6}$ y propuso la creación de varios seminarios conciliares en la capital y pueblos más importantes del arzobispado siendo visitador general en tiempos del prelado Luis de Salcedo y Azcona. ${ }^{7}$ Sin embargo, la confianza que ganó no resultaría suficiente para sacar adelante el proyecto que aguardó un par de décadas al interés del conde de Mirasol y Fernando de Torres Angulo que, hojeando un número de la Gaceta de Madrid de 1781, fueron sorprendidos por la noticia de la erección de dos nuevos obispados. Aunque la documentación no revela cuáles eran y sólo señala que eran "unos pueblos miserables", debían referirse a las diócesis de Ibiza (1782) y Tudela (1783) creadas por entonces y que la predisposición de la Corona les animó a retomar este viejo proyecto como ya hicieran en otra época de grandes cambios en la administración eclesiástica española, la de Felipe II. Dicho y hecho. Después de asegurarse la protección de varios notables de la ciudad, Fernando de Torres presentó su propuesta al ayuntamiento el 14 de enero de 1782 aprovechando las circunstancias de la sede vacante por fallecimiento del arzobispo sevillano Francisco Javier Delgado Venegas.

La Ciudad se avino a la propuesta y aprobó elevar una instancia al rey que realizaron los capitulares José Triano y Andrés Rodríguez, adhiriéndose poco después el cabildo de la iglesia colegial. Para su buen término en la Corte, se nombraron dos agentes, Pedro Salinero y Antonio Manuel de Rojas, y se instó al ayo del Cardenal Infante, Joaquín Ponce de León y Cuevas, para que protegiese la representación. También se aprovechó el

\footnotetext{
${ }^{4}$ MESSA XINETE, Francisco: Francisco de Messa Xinete: su autobiografia, sus hospicios de niñas buérfanas, J. L. Repetto Betes (ed.), Jerez, Centro de Estudios Históricos Jerezanos, 1978, p. 11.

5 AVELLÁ CHÁFER, Francisco: "Beatas y beaterios en la ciudad y arzobispado de Sevilla", Archivo Hispalense, tomo 65 , no 198,1982 , pp. 99-151.

6 MARTÍN RIEGO, Manuel: "Enseñanza y clero parroquial en la archidiócesis de Sevilla (1750-1800)", EA, Escuela abierta: revista de Investigación Educativa, $\mathrm{n}^{\circ}$ 5, 2002, p. 270.

${ }^{7}$ MARTÍN RIEGO, Manuel: La formación intelectual del clero. El seminario conciliar de Sevilla (1831-1931), Sevilla, Caja Rural, 1994, p. 43.

8 ARCHIVO CATEDRAL DE SEVILLA (ACS), Justicia, libro 120, f. 259.
} 
tránsito por la ciudad de Jerez del Conde de Artois, que fue cumplimentado por Fernando de Torres y por el prebendado Francisco de Celis, para que se uniese a la causa aunque no hizo más en principio que hacer llegar la representación a la secretaría de Gracia y Justicia, concretamente, al Marqués de la Hinojosa, oficial primero emparentado con la ciudad de Écija. En todo caso, un negocio de tanta gravedad debía rubricarse por todo el pueblo y correspondía al ramo de Justicia y así lo hizo saber dicho marqués al bailío Francisco Zarzaza y al brigadier Felipe de Carrioza, relacionados con Jerez, en una tertulia en casa del ministro de Marina allá por 1783. Los testimonios subrayan el celo del noble por el expediente jerezano aunque, a su vez, refieren que posiblemente tratara de relanzar con ello el extinto obispado astigitano, conjeturas fundadas solamente en conversaciones de sobremesa. Sea como fuere, el brigadier informó a su hermano Martín, presbítero beneficiado de la parroquia de San Juan, y éste corrió la voz por la ciudad de Jerez que reemprendió la marcha asegurándose de cumplir todas las formalidades. El acuerdo fue renovado (7 de julio de 1783) y firmado por los veinticuatro, diputados, personero, jurados, cabildo eclesiástico y toda persona ilustre siendo a partir de este momento cuando observamos verdaderamente una implicación de la colegial que se ofreció a contribuir por mitad a los gastos del expediente. ${ }^{9}$

A pesar de las recomendaciones ya citadas, la representación no gozó de toda la protección necesaria en la Corte. Ante ella, sólo respondieron los agentes Antonio Manuel de Rojas y Juan García de Santa Colomba, nombrado por el canónigo diputado Manuel Jiménez. No faltaron intentos por parte de la Ciudad de colocar un capitular diputado en Madrid aunque para ello necesitaba de la facultad regia y el Consejo no lo admitió. Nada se menciona, en cambio, del citado agente Pedro Salinero, los patricios Ignacio Ponce de León, su hermano Joaquín y del fiscal del Consejo de Guerra Lorenzo Fernández Gatica, que apenas respondieron políticamente, y sólo el bailío Zarzaza aceptó los poderes del cabildo municipal a finales de 1785. Tampoco faltaron quienes buscaron aprovecharse de la coyuntura: el oficial de la Secretaría de Estado de Marina, Julián de Retamosa, se ofreció a colaborar con Jerez por ser la cuna de uno de sus antepasados pero el tiempo demostró que buscaba una certificación de nobleza para ingresar en la orden de Alcántara. Por ello, la Ciudad no dudó en volver a recurrir al Conde de Artois, que finalmente intercedió para que el documento llegase a Carlos III que lo derivó a la Cámara de Castilla. Examinado por ésta, una real cédula (17 de febrero de 1784) ordenaría la instrucción del caso al regente de la Audiencia de Sevilla que rápidamente contactó con el corregidor de Jerez, Ignacio

\footnotetext{
${ }_{9}^{9}$ ACS, Justicia, libro 120, ff. 258-269 vo.
} 
Retama. La Ciudad acordó presentar sus pruebas a través del Marqués de Casa de Vargas, capitular, que pasó a Sevilla junto al canónigo de la colegial Manuel Fresneña. ${ }^{10}$ Desplazamientos, dietas y comisiones se convirtieron desde entonces en el gran dilema de los jerezanos y, sobre todo, cuando el negocio no dejó de dilatarse con los recursos de Sevilla, encomendados fundamentalmente al vicario Manuel María Pérez, al canónigo Lázaro Fernández Ladreda ${ }^{11}$ y al abogado Juan Pérez Villamil, así como la intervención de Cádiz.

En cualquier caso, los envites de Jerez tardaron años en perder fuerza alentados por falsas esperanzas. En primer lugar, se cotejaron las pruebas aducidas por la colegial en un acto presidido por el alcalde mayor de Sanlúcar de Barrameda, Francisco Javier Chuecos, donde fueron invitados los peritos de la dignidad episcopal, Francisco de Mendoza, del cabildo catedral, Antonio de San Martín y Juan de Lecanda, el licenciado Juan Blanco y Juan Ramírez de Arellano, por la colegial de Jerez, el diputado José Triano, el canónigo Francisco de Ovedos y el racionero Francisco de Celis. Luego, el ayuntamiento se encargó de imprimir algunos ejemplares de un memorial con los servicios de la Ciudad remitido a Felipe IV para la restitución del voto en Cortes, pidió colaboración documental sin éxito a la ciudad de Córdoba con la que estaba hermanada y se ordenó otro cotejo documental (2 de agosto de 1785). El trámite se resolvió con no pocas dificultades: el abogado Mendoza y el subdiácono San Martín se negaron a firmar una diligencia que trataba un pleito no resuelto. ${ }^{12}$ Nos referimos al uso por la colegial de los títulos de real e insigne cuando Sevilla defendió que no era lo primero ni lo segundo pues el título de colegial sólo se admitía por tradición reciente. Este pensamiento lo justifica la defensa hispalense en gestos como el toque de las campanas a maitines (que sólo se produjo después de 1778 y cuya precedencia en la localidad no correspondía a su carácter sino a su antigüedad), el empleo de las capas negras en el coro o la intervención en la mayordomía de fábrica sin la aquiescencia episcopal. ${ }^{13}$

Tampoco falta la falsificación documental denunciada, por ejemplo, por el sevillano Lecanda que enumeraba las irregularidades de la copia de un privilegio original del rey Sancho IV (1 de agosto de la era de 1326): giros narrativos anacrónicos, anomalías en la

\footnotetext{
${ }^{10}$ Ibidem.

11 A partir de 1786, este eclesiástico, que había sido administrador del hospital del Espíritu Santo de la capital además de familiar del prelado Llanes, ocupó la canonjía del fallecido Manuel Fresneña, mentor de la causa jerezana. ARCHIVO GENERAL DEL ARZOBISPADO DE SEVILLA (AGAS), Gobierno, Asuntos Despachados, legajo 60. Carta del arzobispo Llanes al cabildo colegial de Jerez. Sevilla, 25 de marzo de 1786.

12 ACS, Justicia, libro 120. ff. 102-109.

13 AGAS, Gobierno, Asuntos Despachados, legajo 64. Satisfacción de 30 de noviembre de 1787 a una injuriosa representación del cabildo de Jerez:
} 
rueda, en la ordenación de los confirmantes, lábaro mal estampado, cancelaciones, además de "letra como muy gastada y emblanquecida sin duda con objeto a figurar que ha estado en sitio húmedo y llovioso (aunque ahora se sacó de la arquita de plomo) y muchos pedazos al parecer arrancados a propósito para manifestar antigüedad". ${ }^{14}$ Dada la disconformidad de Sevilla y la negativa jerezana a enviar la documentación a la Cámara, argumentando posible extravío, un testimonio indica que Jerez determinó no presentarlos como prueba. En su lugar, exhibieron otras no exentas de críticas. Por ejemplo, fueron evaluadas las murallas, muy particularmente sus adornos geométricos ${ }^{15}$, para inferir la antigüedad y, en consecuencia, la magnitud e importancia del asentamiento xericense en época medieval. El arquitecto Manuel Núñez, maestro mayor de la catedral, y los agrimensores determinaron una extensión de 2.832 varas de longitud y 2.168 de latitud con la que no estaban conformes debido al método empleado que incluía los despoblados o el trazado irregular de las calles. El alcalde mayor de Sanlúcar de Barrameda, juez comisionado, se negó a repetir la prueba. ${ }^{16} \mathrm{Y}$ todo ello, fue sazonado con otros méritos que buscaban destacar la importancia del municipio y que fueron igualmente contestados a tenor de la accidentalidad de muchos: cabeza de partido en la recaudación de rentas provinciales, titular del regimiento provincial de milicias... ${ }^{17}$

Mientras, la sede hispalense ya tenía nuevo arzobispo. El asturiano Alonso Marcos Llanes y Argüelles arribó a fines de 1783 y pronto dispuso una visita pastoral por toda la archidiócesis, muestra de celo que Jerez reclamó a sus predecesores y que ahora sumaba como una prueba más en el discurso de independencia. Aunque todo hace indicar que el prelado fue recibido a fines de 1784 como manda el protocolo, el pleito continuó haciéndose más encarnizado y, por tanto, más costoso al año siguiente. ${ }^{18}$ Además, el arzobispo Llanes bajó la participación del cabildo de Jerez en las rentas por administración de granos y determinó suspender la apropiación de misas alcanzadas, sin razón de ser tras la conclusión de las obras de la colegial. De nada sirvió la misión encomendada al capuchino Diego José de Cádiz en la Cuaresma de $1785^{19}$ para calmar los ánimos que poco después se manifestaron encendidos en una carta de los diputados Ovedos y Celis al rey (21

\footnotetext{
${ }^{14}$ ACS, Justicia, libro 120, f. 139 vo.

15 POMAR RODIL, Pablo Javier: "Entre el orgullo ciudadano y la falsificación erudita: la decoración geométrica de las puertas de Jerez de la Frontera en la historiografía local del siglo XVIII", Cuadernos de arte de la Universidad de Granada, no 34, 2003, pp. 81-95.

16 ACS, Justicia, libro 120, ff. 120-131.

17 ACS, Justicia, libro 121, f. 346.

18 ACS, Justicia, libro 120, ff. 258-269 vo.

19 AGAS, Gobierno, Asuntos Despachados, legajo 59. Carta del vicario Manuel María Pérez al secretario arzobispal Ignacio Almoriña. Jerez, 21 de enero de 1785.
} 
de septiembre de 1787) donde intentaron abortar sin éxito una nueva visita por los incesantes atropellos del canónigo Ladreda y el partidismo de la Audiencia de Sevilla. ${ }^{20}$

Respecto al gasto, el 13 de enero, el Marqués de Casa Vargas informaba que ya había consumido más de 12.000 reales y el agente otros 6.000 siendo necesaria una nueva partida que no tardó en llegar. El 31 de enero, el ayuntamiento libraba 10.000 reales a los que se sumaron 3.000 pesos el 16 de diciembre de 1785, a instancias de Zarzaza. ${ }^{21}$ Las elevadas sumas que se sucedieron y el miserable estado del fondo público (deuda cercana al millón de reales ${ }^{22}$ ) alertaron al corregidor Ignacio Retama que prohibió los libramientos sin permiso del Consejo de Castilla al que recurrió la ciudad de Jerez a través de los veinticuatro Joaquín Bernal, Antonio Antúnez, la junta de propios, los diputados del común y el síndico personero. En un informe fechado el 22 de julio de 1785, estos señalaron la utilidad de la mitra $y$, fundamentalmente, el derecho a la defensa que le conminaba la real cédula de 1784. El Consejo, por decreto de 2 de diciembre, denegó la instancia de la Ciudad pero no se desistió acordando suplicar al corregidor, ya en 1786, para que suspendiese el apremio que les obligaba a devolver las cantidades extraídas del arca con este fin. De nuevo, la petición de demora se amparaba en las promesas que le transmitían el bailío Zarzaza o García de Santa Colomba sobre la rápida y favorable conclusión del pleito y los recursos dirigidos al rey por el ayuntamiento y los electores de las parroquias. La disputa no concluyó tan pronto como auguraban los agentes pero el Consejo, en su dictamen del 7 de julio de 1787, alivió la espera permitiendo la saca de 40.000 ducados del fondo de propios a través del diputado del común y bajo la condición de justificar las cuentas ante el organismo central. Llegados a este punto, parece indudable que el negocio centraba todo el interés de Jerez por aquellos años como también demuestra la recomendación realizada por el cabildo municipal a los superiores del dominico fray Juan Díaz tras hacer alusión a la mitra jerezana en el sermón de la Natividad de la Virgen de $1785 .^{23}$

A todo lo anterior, debemos añadir que, a partir de 1786, entró en escena un tercero en discordia: la iglesia de Cádiz que, haciéndose valer como heredera del obispado asidonense, aprovechó el pleito para reclamar ciertos territorios atribuidos a la diócesis visigótica. A falta de pruebas sobre la extensión de la antigua iglesia, la ocasión merecía

\footnotetext{
20 AGAS, Gobierno, Asuntos Despachados, legajo 64. Representación de los diputados Ovedos y Celis al rey. Jerez, 21 de septiembre de 1787.

21 ACS, Justicia, libro 120, ff. 258-269 vo.

22 AGAS, Gobierno, Asuntos Despachados, legajo 60. Carta de Joaquín Bernardo de Quirós al arzobispo Llanes. Madrid, 2 de mayo de 1786.

${ }^{23}$ ACS, Justicia, libro 120, ff. 258-269 vo.
} 
intervenir pues Sevilla reconocía dicho traslado. Sin embargo, ni ésta accedió a conceder término alguno ni Jerez aceptó la oferta gaditana de una concatedralidad. ${ }^{24}$

A partir de 1788, carecemos de la riqueza informativa proporcionada por el vicario Manuel María Pérez pero podemos cerrar los últimos años de la centuria con otros datos de la secretaría del arzobispado de Sevilla y la bibliografía. De estos se concluye el alto coste del litigio así como el encastillamiento de las distintas defensas que jugaban al desgaste del contrario. El arzobispado tomó el recurso de denunciar sistemáticamente la presencia irregular de eclesiásticos jerezanos en la $\operatorname{Corte}^{25}$ actuando su procurador de forma independiente a los representantes del cabildo catedral y la Ciudad, eventualidad que Jerez no dejó de denunciar a la Cámara y logró aunque ya en $1793 .{ }^{26}$ La colegial, por su parte, incluso hubo de vender las fincas donadas por el canónigo Fernando Ramos para continuar la causa. ${ }^{27}$ En general, debía respirarse un clima de cansancio. Así lo hace notar el obispo auxiliar Agustín Ayestarán cuando en la visita de 1788 escribió al arzobispo Llanes:

En los asuntos pendientes relativos a la dignidad de V.E. observo alguna fermentación y proficua entre los mismos sostenedores de nueva mitra, patronato y de los demás particulares pero con mucha timides, y covardía; ellos se van convenciendo de la dificultad y dilación del negocio principal, y aunque alguna otra ves se procura difundir noticias lisonjeras, ya por repetidas experiencias conocen la vanidad y falsedad de ellas: generalmente se advierte inclinación a la dignidad y amor a la persona de V.E. entre la nobleza, pueblo y especialmente el clero.

Aún en los pocos que V.E. conoce mui bien, que llevan el pendón de la rebelión, se reconoce cierto abatimiento y languidez efecto del progreso y aspecto poco favorable que han tomado los negocios después de tan crecidos dispendios, y lo que es más porque ven desecadas las fuentes y estinguidos los principales manantiales de sus recursos. Son apuros mui grandes, en los que se ven metidos con las resultas de la visita personal de V.E. en este estado considerándolo con poco remedio, algo más frescos y desapasionados lloran y gimen de no haver echo otra cosa que promover el derecho de un tercero desconocido y contribuir imprudentemente a su favor, excitándole demasiado las ganas y el apetito de engrandecer y estender el corto recinto a que le redujo la providencia. Este mal es el mayor en la consideración de los mismos promovedores y más sensible que sería a nosotros y lo miran más cerca de lo que deven y esta dependencia aún imaginada les asusta más que la que procuraron sacudir injustamente. Quiera Dios que abran los ojos para conocer perfectamente la miseria a que se ven reducidos

\footnotetext{
24 Ibidem.

${ }^{25}$ Hay un testimonio sobre la orden real de expulsión de la Corte de Antonio de Morla, abad de la colegiata. AGAS, Gobierno, Asuntos Despachados, legajo 71. Carta de Cayetano de la Peña al vicario Manuel María Pérez. Madrid, 14 de abril de 1789.

${ }^{26}$ ACS, Justicia, libro 120, ff. 263-264.

${ }^{27}$ GARCÍA ROMERO, Francisco Antonio y VEGA GEÁN, Eugenio José: “La larga marcha...”, art. cit., p. 41.
} 
por su temeridad y haciendo el debido uso de esta luz hayan el correspondiente esfuerzo para unirse seriamente con el Prelado que Dios les a dado. ${ }^{28}$

Lejos del apasionamiento de las letras del auxiliar, es cierto que la tempestad judicial amainó. Varias solicitudes de Jerez apremiando la resolución del rey ${ }^{29}$ y escritos de resistencia y peticiones de prórroga de Sevilla tras la muerte del arzobispo Llanes en $1795^{30}$, anteceden a las últimas noticias que conocemos para el siglo XVIII y que deja en agua de borrajas las aspiraciones xericenses. La primera, se trata de las alegaciones en derecho de Julián de Iturralde que nada consiguieron frente a la sentencia contraria a la mitra de Jerez en $1798 .{ }^{31}$ La segunda, corresponde al borrador de una carta de Godoy al cabildo catedral de Sevilla (28 de enero de 1799) donde advierte sus deseos de satisfacerlo en la vista del caso, señal que demuestra la obstinación jerezana y que la sentencia de 1798 no fue, ni mucho menos, el punto y final. ${ }^{32}$

\section{LA MITRA ASIDONENSE, ¿RESTAURACIÓN O ESTABLECIMIENTO?}

La primera pregunta que nos asalta al verificar los testimonios jerezanos es si realmente era factible solicitar una traslación o, por el contrario, el término creación era más adecuado a tenor de lo que defendían Sevilla y Cádiz. Para su respuesta nos serviremos de la refutación de las pruebas filológicas e históricas acreditadas por Jerez que, desde el comienzo y según la defensa hispalense, vaciló entre el traslado y la erección porque lo importante no eran los medios sino el fin:

Por si acaso no pudiere probar este despojo, que da por tan sentado, recurre en segundo lugar a la idea de nueva erección de obispado, pidiendo que sea elevada a Cathedal su Yglesia Colegiata de San Salvador y señalada la Diócesis y territorio que haya de pertenecer al nuevo obispado. ${ }^{33}$

\footnotetext{
28 AGAS, Gobierno, Asuntos Despachados, legajo 68. Carta del auxiliar Ayestarán al arzobispo Llanes. Jerez, 7 de noviembre de 1788 .

${ }^{29}$ ACS, Justicia, libro 121, ff. 385-387.

30 ACS, Secretaría, Correspondencia de la Diputación de Negocios al agente en Madrid, libro 511. Carta desde Sevilla, 30 de abril de 1794; carta desde Sevilla, 25 de marzo de 1795. Fue concedida la suspensión: carta desde Sevilla, 3 de junio de 1795.

31 GARCÍA ROMERO, Francisco Antonio y VEGA GEÁN, Eugenio José: “La larga marcha...”, art. cit., p. 41.

32 ACS, Secretaría, Libro copiador de cartas del Cabildo, 497, f. 190. Carta de Godoy al cabildo catedral de Sevilla. Madrid, 28 de enero de 1799.

33 ACS, Justicia, libro 120, f. 2.
} 


\section{Etimología y testimonios sobre el antiguo territorio de Asido}

Antonio de Mesa Xinete fue el principal estudioso ilustrado del topónimo Jerez en su desacreditada labor de identificación con la antigua ciudad de Asido. Sin embargo, merece la pena que desarrollemos cómo justifica parte de la inventiva que cautivó a algún erudito del momento. ${ }^{34}$

Según el capitular jerezano, el vocablo Asidonia proviene de la voz Astidonia, unión de los topónimos Asta Regia y Asido Cesariana que dieran los romanos al lugar en tiempos de Julio César. Sin embargo, las confusas descripciones de Plinio que nos remite el documento del arzobispado los vincula a dos asentamientos diferentes: el primero sobre el río Betis y el segundo en tierra adentro o el Mediterráneo. De esta dialéctica se desvincularía el padre Flórez a pesar de su amistad con Mesa pues, como recalca el mismo testimonio, "la pasión por engrandecer la patria hace milagros" y la unión de distintas ciudades acabaría formando "un monstruo como los que se configuran mitad peces, y mitad hombres". ${ }^{35}$ En cualquier caso no parece que fuera ni una ni la otra. El anónimo que escribe relega el obispado de Asta a la fantasía del padre Román de la Higuera que bebe de los cronicones de Flavio Dextro o Marco Máximo. El obispado de Asido, por otra parte, tampoco se situaría en la actual Jerez según la división de Constantino que rebate la iglesia de Sevilla junto a su fiador más antiguo, el moro Rasis: "los yerros que contiene la misma escritura de la división son tan grotescos que no cabían sino en la barbarie de un moro y en la ignominia que le toca de tener de la historia de las Yglesias y de Ntra. Santa Religión". ${ }^{66}$

Posteriormente, según Antonio Mesa, los musulmanes la bautizaron como XeirazXerez en posible correspondencia con la patria de su principal conquistador, derivación que no comparte el padre Roa que prefiere llamarla Ceret. El historiador andalusí Ahmad ibn Muhammad al-Razi, también conocido como el moro Rasis, la identifica en el siglo X como Xerez Saduña, sobrenombre que Mesa Xinete rápidamente relaciona con un pago de huertas cercano llamado Cidueña y que el arzobispo don Rodrigo Jiménez de Rada, la Crónica de Alfonso X y otros privilegios posteriores utilizan indistintamente con el de Sidonia hasta el reinado de Enrique II que la intitula "de la Frontera". Por tanto, el sobrenombre Sidonia o Sidonis, según el dictamen del arzobispado de Sevilla, no probaría nada en la medida que otras poblaciones (Medina, Alcalá de los Gazules...) también lo

\footnotetext{
${ }^{34}$ ACS, Justicia, libro 120, ff. 2-69.

35 ACS, Justicia, libro, 120, f. 33.

36 ACS, Justicia, libro 120, f. 37 vo.
} 
usaron en sus escrituras antiguas y las gracias concedidas no tuvieron el fin probatorio que el capitular les atribuye.

Ésta es la probanza etimológica de Mesa Xinete pero, ¿qué lugar asigna en su memorial a la actual población de Medina Sidonia? El eclesiástico, contrastando diversos testimonios del moro Rasis, concluye que Medina Sidonia fue denominada Asila (Refugio) por poseer un templo dedicado a Hércules ${ }^{37}$ en tiempos de los fenicios y que, destruida posteriormente, no se repobló hasta la época musulmana con el nombre de Sidón. Una débil argumentación que, según el defensor sevillano, no hizo más que reforzar la importancia de esta ciudad gaditana: adjudicándole un templo en la Antigüedad cuya fama trasciende los siglos y un topónimo, Sidón, que posiblemente no habría recibido de hallarse completamente destruida. Los vestigios materiales de la época romana y goda ${ }^{38}$ refuerzan la tesis de que Asido (Medina Sidonia) fue una de las principales colonias de los itálicos en Andalucía y así lo ponen de relieve ciertos historiadores como Sebastián de Covarrubias o Rodrigo Méndez de Silva que argumentan su fundación fenicia (Sidón), su transformación en colonia romana (Asido) y su principalidad en tiempos de los musulmanes (Medina). ${ }^{39} \mathrm{~A}$ estos historiadores podrían sumarse los nombres de Ambrosio de Morales, Juan de Mariana o Rodrigo Caro. ${ }^{40}$

Sin embargo, aunque Jerez no fuera la antigua Sidonia, esta circunstancia no explica que a lo largo de su historia no hubiese ostentado la sede episcopal como comprueban Vega y García ${ }^{41}$ o López Fernández ${ }^{42}$ y esta realidad fue combatida por Sevilla por razones obvias. En primer lugar, el empeño de Alfonso X de constituir a Cádiz en cabeza de obispado obligó a la archidiócesis hispalense a desprenderse de cierto territorio arrebatado a los musulmanes que, por otra parte y en teoría, eran una concesión real limitada a la reconquista de las antiguas titulares sufragáneas. Así lo afirma la defensa hispalense cuando revela la entrega de los diezmos de Antequera (tutelados por privilegio de Fernando III desde 1252) a la restaurada iglesia de Málaga en el siglo XV. Por tanto,

\footnotetext{
37 Vega y García confirman su presencia. VEGA GEÁN, Eugenio José y GARCÍA ROMERO: Francisco Antonio, Origen e Historia del antiguo obispado asidonense, Jerez, Centro de Estudios Históricos Jerezanos, 1997, p. 28.

38 La documentación menciona una piedra en Medina Sidonia con la fecha de consagración del obispo San Pimenio (629) que estuvo en el IV Concilio de Toledo. ACS, Justicia, libro 120, f. 40. Actualmente, esta lápida se encuentra en la ermita de los Santos Mártires de dicha localidad. VEGA GEÁN, Eugenio José y GARCÍA ROMERO, Francisco Antonio: Origen e Historia..., op. cit., p. 78.

${ }^{39}$ ACS, Justicia, libro 120, f. 15 vo.

40 ACS, Justicia, libro 120, f. 30.

${ }^{41}$ GARCÍA ROMERO, Francisco Antonio y VEGA GEÁN, Eugenio José: “La larga marcha...”, art. cit., p. 40. Para profundizar sobre la trayectoria del obispado asidonense hasta el siglo XII recomendamos de estos mismos autores: ---, Origen e Historia..., op. cit.; ---, Una comunidad andalusí olvidada. El obispado mozárabe asidonense, Jerez, Peripecias Libros, 2013.

${ }^{42}$ LÓPEZ FERNÁNDEZ, Antonio: “La diócesis...”, art. cit., p. 576.
} 
parece evidente que renunciar a Jerez (pues Medina Sidonia se encontraba dentro de los límites de Cádiz) podía alentar la reivindicación de otras localidades sevillanas como Écija (Astigi) o Niebla (Elepa) de la misma manera que el traslado no se concibe sin la mención de Asidonia en el título de los obispos de Cádiz y sin la totalidad de sus territorios. Asimismo, presentar la erección gaditana como traslación del obispado asidonense podía presentar la ventaja de que todo quedara igual pero también sus inconvenientes: las reivindicaciones de Cádiz que efectivamente se produjeron desde 1786 reclamando la totalidad del territorio de dicha iglesia visigótica. A pesar de los riesgos, Sevilla salía ganando con este planteamiento pues fuentes originales que precisaran los antiguos límites geográficos eran escasas, dilema que no pareció importar al representante del cabildo catedral gaditano, Domingo Gómez:

Si en el día se estimara conveniente restablecer la antigua sede de Abdera, Elepa o Astigi, ¿sería posible que el estudio de los más eruditos anticuarios pudiese apurar cada uno de sus antiguos limites? Creemos que no, ¿y por esto se devería dejar de hacerse la restauración de la Sede, estimándola necesaria o conveniente? Tampoco previniéndonos el derecho que en semejantes casos el prudente arbitrio del juez debe governar por aquellos argumentos, presunciones y congeturas probables que puedan inclinar su juicio a elegir lo que estimase más fundado, verosímil y conveniente. ${ }^{43}$

En cualquier caso, la ausencia de testimonios tranquilizó a la defensa sevillana como demuestran las licencias que se tomaron:

Negar que se hizo una cosa que permanece hecha es el colmo de la inconsideración (...) Abran los ojos los de Xerez y miren qual distrito ocupa hoy el obispado de Cádiz. ¿No son las tierras, pueblos y feligresías del antiguo obispado Sidonense? ¿Estuvo aquel obispado fundado en la luna o en otro sitio de España? ${ }^{44}$

Tras la reconquista de Jerez en 1264, Alfonso X cristianizó los recintos sagrados del Islam con la erección de una iglesia colegial y cinco parroquias. En el siglo XIV, se fundaron las parroquias extramuros de San Miguel y Santiago y comenzaría el auge de la colegiata que alcanzó su plenitud en el siglo XVI cuando su collación comenzó a despoblarse y los beneficios económicos se resintieron. El testigo lo tomaría la parroquia de San Miguel que asistió en lugar privilegiado a las estrategias de ennoblecimiento de la ciudad lanzadas en la Edad Moderna. Una de ellas, la identificación por los eruditos locales

${ }^{43}$ ACS, Justicia, libro 121, f. 445.

${ }^{44}$ ACS, Justicia, libro 120, f. 40.

Trocadero, no 26 (2014), ISSN 0214-4212, pp. 53-74 
de la ciudad italiana de Asti con el antiguo asentamiento de Asta Regia en el término de Jerez para atraerse los martirios de los santos Eutiquio, Esteban y Honorio. ${ }^{45}$ La otra estrategia fue la que venimos reseñando acerca de la restauración del obispado asidonense que conoció otros intentos antes del siglo XVIII. Nos referimos, por ejemplo, a las coyunturas propiciadas por la toma de Málaga (1487) o la creación del obispado de Valladolid (1580).

\section{Cádiz, la tercera en disputa}

Enarbolando el argumento de la restauración gaditana, la sede hispalense se esforzó en demostrar que Jerez siempre perteneció a su jurisdicción argumentando que la iglesia de Cádiz accedió a erigirse sin ella. Sin embargo, la defensa no señala que, probablemente, el primer electo gaditano, fray Juan Martínez, no tuvo elección si quería gobernar y que el rey Alfonso X debió negociar con Sevilla para cumplir el deseo de hacer de Cádiz su ilustre panteón (de la misma manera que su padre lo había hecho en la capital hispalense) sin abrir un nuevo frente entre los muchos que ya tenía.

El 2 de febrero de 1266, una bula de Clemente IV, a instancias del rey Alfonso X, erigió la diócesis de Cádiz. ${ }^{46}$ Según el arzobispado de Sevilla, una traslación del obispado asidonense documentada por la copia de ciertas bulas ${ }^{47}$ y la localización circunstancial de su prelado en Medina Sidonia, tesis que ha sido defendida hasta la actualidad por Demetrio Mansilla $^{48}$ o Antón Solé ${ }^{49}$. Entre las primeras, encontramos una de Urbano IV que la defensa de Sevilla cita a través de otra dada por Clemente IV el 29 de enero de 1266 donde comisionaba al obispo de Ávila a oír instructivamente al sevillano y a trasladar el obispado asidonense si no encontraban documentación en contrario. Otra de Clemente IV de 26 de mayo de 1267, copia autentificada, ordenaba lo mismo a los obispos de Cuenca y Córdoba. No obstante, a pesar de la abundancia de citas y reclamos, la documentación hispalense muestra que, aunque se dudó en principio sobre la propiedad de Cádiz y su isla, finalmente

45 GARCÍA ROMERO, Francisco Antonio y VEGA GEÁN, Eugenio José: "El cristianismo en la zona Xericense tras la reconquista", XX Siglos, volumen 16, n 54, 2005, pp. 24-38.

46 ACS, Justicia, libro 120, f. 57.

47 Charlo y Piqueras hacen un estudio filológico y diplomático de las dos bulas de Clemente IV. La primera, de 2 de febrero de 1266, bien podría corresponder con la que datamos el 29 de enero y que comisionaba al obispo de Ávila a investigar y, en su caso, trasladar la diócesis asidonense. No refiere que se hiciera efectivo. La segunda, de 1267, recoge la orden dada a los obispos de Cuenca y Córdoba para consagrar al electo gaditano. CHARLO BREA, Luis y PIQUERAS GARCÍA, Belén: "Bulas fundacionales de la Diócesis de Cádiz (II)", Documenta \& Instrumenta, no 4, 2006, pp. 23-45.

48 MANSILLA REOYO, Demetrio: Geografía eclesiástica de España: estudio histórico-geográfico de las diócesis, Roma, Iglesia Nacional Española, 1994, tomo II, p. 185.

49 ANTÓN SOLÉ, Pablo: "La diócesis de Cádiz en época medieval (siglos VIII-XV)", en J. Sánchez Herrero, Historia de las diócesis españolas: Sevilla, Huelva, Jerez, Cádizy Ceuta, Madrid/Córdoba, BAC, 2002, p. 631. 
se cedió. Y todo ello con el hipotético dominio de un derecho pontificio que les garantizaba la suspensión de la causa (hasta la conquista de Medina Sidonia) si no se dilucidaba este aspecto. Por tanto, ¿estaba reconociendo Sevilla una obviedad o simplemente recalculó el precio de la cesión para no perder el favor del monarca además de otros territorios si se lograba la restauración efectiva? Según Gómez Serrano, Cádiz únicamente recibió siete pueblos incorporándose después la "Real Ysla", Chiclana, Puerto Real, Conil, Paterna, San Roque, Los Barrios y Castellar hasta completar los quince que contaba en el siglo XVIII. ${ }^{50}$ Sus límites quedaron imprecisos entre los ríos Guadalete y Guadiaro. ${ }^{51}$ Dicho esto, parece evidente que la iglesia metropolitana apostó por la solución menos traumática, máxime en tiempos de enfrentamientos donde toda atención se desviaría hacia problemas mayores con un mínimo acuerdo. En el arzobispado de Valencia, donde la ciudad de Játiva intentó restablecer la sede visigótica de Saetabis en el siglo XIV, ni siquiera se llegó a eso y la posterior erección del obispado de Orihuela anuló cualquier posibilidad de restauración. ${ }^{52}$ Recogiendo las palabras de Nieto Soria, parece que la creación de las diócesis tras la reconquista se atuvo preferentemente al juego de poderes entre el rey y los metropolitanos antes que a la reconstrucción de la vieja organización eclesiástica. $^{53}$

Otro argumento por el que Sevilla verifica el traslado fue el emplazamiento ocasional de los obispos gaditanos en Medina Sidonia. Por ejemplo, en el siglo XV por "las extorsiones de parte del cabildo secular" o en el siglo XVI tras la invasión de los ingleses. ${ }^{54}$

\footnotetext{
50 ACS, Justicia, libro 121, f. 474.

${ }^{51}$ GARCÍA ROMERO, Francisco Antonio y VEGA GEÁN, Eugenio José: "El cristianismo...”, art. cit., p. 25. Estos mismos autores circunscriben el obispado visigótico al antiguo conventus gaditanus así como a ciertos pueblos del convento jurídico de Sevilla, al norte del Guadalate, muchos despoblados ya en dicho momento: Nabrissa (Lebrija), Colobana o Colobona (Trebujena), Asta Regia (Mesas de Asta, junto a Jerez), Turris Caepionis (Chipiona), Siarum (cerca de Las Torres de Alocaz), Carissa (al norte de Bornos y Espera), Salpensa (al sur de Utrera), Iptuci (junto a Prado del Rey), Urgia o Ugia (entre Las Cabezas de San Juan y Las Torres de Alocaz), Lacca (en el cortijo de Casablanca en Arcos), Callet o Callenses (entre Montellano y Morón), Arsa o Arcobriga (Arcos), Lucis Dubiae Fanum (en el término de Sanlúcar de Barrameda), Ceret (Jerez), Calduna y Turirecina (en los términos de Arcos y Bornos), Lacilbula (cerca de Grazalema), Ocuri (cerca de Ubrique), Saepo o Usaepo (cerca de Cortes de la Frontera), Laccipo o Blaccipo (cerca de Casares), Oba o Succuba (cerca de Jimena), Barbesula o Berbesula (al sur del Guadiaro), Saltus (junto al Guadiaro), Calpe (Gibraltar). Carteia (desembocadura del Guadarranque), Portus Albus y Tingentera (cerca de Algeciras), Iulia Traducta (Tarifa), Baelo (Bolonia), Baesippo (en Barbate), Besaro (posiblemente Vejer), Cimbii (término de Rota), Portus Menesthei (inmediaciones de El Puerto), Portus Gaditanus (quizás en Mesa de Bolaños), Ad Pontem (zona de San Fernando), Gades (Cádiz), Ad Herculem (cerca del templo de Hércules de Sancti Petri), Herculis Fanum (en Chiclana), Mergablum (en Conil), Asido (Medina Sidonia), Saguntia (término de Jerez), Lascuta (en Alcalá de los Gazules), entre otros. VEGA GEÁN, Eugenio José y GARCÍA ROMERO, Francisco Antonio: Origen e Historia..., op. cit., pp. 64-67.

52 RAMÍREZ ALEDÓN, Germán: "La erección de nuevas sedes episcopales en el reinado de Felipe II: el caso de la ciudad de Xátiva", Revista de historia moderna: Anales de la Universidad de Alicante, n 17, 1997-1998, pp. 235-248.

53 NIETO SORIA, José Manuel: "La fundación del obispado de Cuenca (1117-1183): consideraciones político-eclesiásticas”, Hispania Sacra, volumen 34, nº 69, 1982, p. 130.

${ }^{54}$ ACS, Justicia, libro 120, f. 67.
} 
Eventualidades que justifican por sí solas el movimiento de los obispos, sobre todo, teniéndose en cuenta que no abandonaban sus dominios. Además, estos prelados nunca adoptaron el título de Asidonia aunque sí el de Algeciras ${ }^{55}$, circunstancia que la defensa sevillana explica por ser el primer asiento de la cátedra asidonense en tiempos apostólicos. ${ }^{56}$ Como vemos, una historia con tantos años como pocas fuentes para poderla corroborar.

Con estos antecedentes, intervino la diócesis de Cádiz en el pleito a partir de $1786 .{ }^{57}$ Dos razones articularon su representación: reclamar el territorio de la antigua iglesia de Asidonia para incrementar las rentas y auxiliar en su necesidad a Jerez, que comprendieron en aquella. La primera causa quisieron apoyarla en la crecida población extranjera que soportaba Cádiz. La segunda razón, en la lejanía a la capital, el desinterés episcopal y el importante vecindario xericense. Como solución, el cabildo catedral y el obispo de Cádiz propusieron el establecimiento de una concatedral en Jerez con un vicario general permanente a la manera del obispado de Calahorra y Santo Domingo de la Calzada. ${ }^{58}$ Claro está, el arzobispado hispalense no toleró este atropello y, desde el comienzo, buscó los flancos débiles de la exposición gaditana: ¿cómo pensaba la iglesia de Cádiz resolver los problemas espirituales de Jerez si denunciaba la escasa cobertura que recibía su heterogénea población? ¿Qué obtenían los jerezanos con una concatedral y un vicario si en dicho momento ya contaban con vicario foráneo, juzgado de testamentos e incluso mesa de examinadores sinodales? Realmente, Jerez ganaba poco con esta alianza y se aventuró a continuar sola en el pleito. ${ }^{59}$

A pesar de ello, Cádiz no se rindió. Era una buena oportunidad para ampliar el poder de su iglesia con más fieles y rentas a pesar del testimonio de Sevilla que consideraba sus beneficios económicos (344.511,10 reales líquidos, según quinquenio de 1780) suficientes e incluso decorosos habida cuenta del corto número de pueblos. ${ }^{60}$ Pensamientos que, como vemos, compartieron los capitulares jerezanos:

...aun quando Cádiz estubiese actualmente en posesión de este territorio con un derecho tan constante y tan notorio que no admitiese la más leve contradicción; Xerez devería emprender y efectivamente emprendería, igual pretención (...) porque cualquiera desmembración que en tal caso se hiciese a la Santa Yglesia y Obispado de Cádiz sería de ningún perjuicio en atención a las cuantiosas y superabundantes rentas que obtiene. ${ }^{61}$

${ }^{55}$ GARCÍA ROMERO, Francisco Antonio y VEGA GEÁN, Eugenio José: “La larga marcha...”, art. cit., p. 40.

56 ACS, Justicia, libro 120, f. 67.

57 ACS, Justicia, libro 120, f. 239.

58 ACS, Justicia, libro 120, ff. 222-226.

${ }^{59}$ ACS, Justicia, libro 120, ff. 243-244 vo.

${ }^{60}$ ACS, Justicia, libro 120, f. 227.

${ }^{61}$ ACS, Justicia, libro 120, f. 243. 


\section{LAS JUSTAS CAUSAS PARA LA ERECCIÓN DE NUEVO OBISPADO}

Agotado el recurso histórico, Jerez apostó por lustrar aquellos condicionantes exigidos por la extravagante Salvator Noster para la erección de nuevos obispados. Esencialmente, dos: la necesidad pastoral y una capacidad económica demostrada para el sostenimiento del culto, el clero y los seglares a través del ejercicio de la caridad sin perjuicio notable de la diócesis que se divide. $^{62}$

\section{Población, iglesia y territorio: el pasto espiritual}

Según el Plan de Curatos del arzobispado, desarrollado durante varias décadas a fines del siglo XVIII, la vicaría de Jerez contaba con 8.081 vecinos y 25.161 personas de comunión. ${ }^{63}$ Esta realidad se acerca a los vecindarios que ofrecen los censos civiles de Ensenada $(7.033)^{64}$ y Aranda $(7.033)^{65}$ mientras se aleja algo más de la cifra de Floridablanca (10.112). ${ }^{66}$ Aunque no se ajusta al dato proporcionado por la defensa jerezana (8.800 vecinos), tampoco resulta descabellado como critica Sevilla ${ }^{67}$ que lo compara a los 9.000 vecinos de un testimonio de 1688 para resaltar su decadencia. ${ }^{68}$ Sin embargo, poco después, la defensa hispalense oculta o no percibe la notable diferencia que se establece entre la cifra de vecinos que adjudica para 1791 (5.081) y la que establece el Plan de Curatos publicado en dicho año, circunstancia que evidencia la adulteración de la información o los errores del plan beneficial atribuibles a su larga gestación. En cualquier caso, el arzobispado se afanó por demostrar que no contaba con un exceso de parroquias (sólo 260, incluidas las filiales, frente a las 1.405 de Burgos o las 450 de Santander ${ }^{69}$ ) y que la distancia entre Jerez y la capital no superaba las quince o dieciséis leguas (ocho horas de viaje con diligencia de ruedas; trece horas por correo ordinario; un día a paso de caballería). ${ }^{70}$ Precisamente, el trayecto a la capital motivó otra queja del clero que acusaba a Sevilla de las molestias y el coste del viaje para recibir o renovar las órdenes y licencias cuando decían superar las 2.000

\footnotetext{
${ }^{62}$ Dicha extravagante permitió al papa Juan XXII dividir el obispado de Tolosa. ACS, Justicia, libro 120, f. 191.

${ }^{63}$ LLANES Y ARGÜELLES, Alonso Marcos: Plan de erección y dotación de curatos del arzobispado de Sevilla, Sevilla, Imprenta de la Dignidad Arzobispal, 1791, pp. 59-64.

${ }^{64}$ ARCHIVO GENERAL DE SIMANCAS (AGS), Dirección General de Rentas, 1a Remesa, Catastro del Marqués de la Ensenada, Respuestas Generales, libro 563. Digitalizado: http://pares.mcu.es/Catastro/ [consultado el 19-08-2014].

65 REAL ACADEMIA DE LA HISTORIA (RAH), Censo de Aranda, signatura 9/6167.

${ }^{66}$ AAVV: Censo de Floridablanca, Madrid, INE, 1987, tomo I.

${ }^{67}$ ACS, Justicia, libro 120, f. 182.

68 ACS, Justicia, libro 121, f. 188 vo.

${ }^{69}$ ACS, Justicia, libro 121, f. 237.

70 ACS, Justicia, libro 120, f. 198.
} 
capellanías, además de otras obras pías y patronatos. ${ }^{71}$ Una cantidad, por otra parte, que resulta excesiva, si la comparamos con las 957 capellanías y 55 patronatos que contabiliza Martín Riego en 1798, aunque no menor. ${ }^{72}$ Con todo, la defensa hispalense no dejaba de referir que, para cuestiones administrativas, la ciudad ya contaba con una mesa de examinadores e incluso con un juzgado de testamentos. ${ }^{73}$

La fábrica de la iglesia colegial, postulante a catedral, tampoco pasó el examen formal de los peritos del arzobispado. Esta iglesia del Salvador fue víctima del infortunio causado por la bajada de rentas de su distrito desde el siglo XVI y el terremoto de 1679 que llevó a su demolición. La nueva planta, de cinco naves con 69 varas castellanas de longitud y 54 de latitud trazada por Diego Moreno Meléndez ${ }^{74}$ y que se ejecutó durante cerca de un siglo $^{75}$, no satisfizo al maestro mayor de la catedral que, al respecto, dijo "no ser este edificio de todo el arreglo y magnificencia que proponen los peritos de Xerez y esto se entiende solos reparos a la vista, que si se llegase a tocar con regla y compás tal vez resultarían otros maiores" ${ }^{76}$

Aprovechando las ausencias de algunos de los últimos prelados en la sede hispalense, una de las principales críticas de Jerez giró en torno a la visita pastoral que se delegó en varias ocasiones. Entre las principales obligaciones del prelado se encontraba la visita de la diócesis para que, el mejor conocimiento de las costumbres de clérigos y seglares, inspirara su gobierno. En ello insistieron diversos tratadistas modernos como Bartolomé de los Mártires, Domingo de Soto o fray Luis de Granada además del propio Concilio de Trento. ${ }^{77}$ Sin embargo, otros teóricos también apuntaron hacia la delegación por impedimento legítimo, caso del italiano Alessandro Sperelli ${ }^{78}$, a la que se recurrió de manera habitual en diócesis extensas o con relieve accidentado, como apunta LópezGuadalupe para Granada. ${ }^{79}$ En este sentido, el amplio arzobispado de Sevilla no fue una excepción pues contó formalmente con siete visitadores para las tres veredas en que se

\footnotetext{
71 ACS, Justicia, libro 120. ff. 148-153.

72 MARTÍN RIEGO, Manuel: "Las capellanías en la Archidiócesis de Sevilla: siglo XVIII”, Isidorianum, volumen 1, $\mathrm{n}^{\circ}$ 1, 1992, pp. 171-204. El historiador contabiliza 7.780 capellanías y 794 patronatos en el arzobispado sin incluir las fundaciones de las parroquias de la ciudad de Sevilla y la catedral.

73 ACS, Justicia, libro 120, f. 199 vo.

${ }^{74}$ POMER RODIL, Pablo Javier: "Diego Moreno Meléndez, autor de la planta de la Colegiata de Jerez de la Frontera", Laboratorio de Arte, no 14, 2001, p. 252.

75 ACS, Justicia, libro 121, f. 410.

76 ACS, Justicia, libro 120, f. 129 vo.

77 TELLECHEA IDÍGORAS, José Ignacio: El obispo ideal en el siglo de la Reforma, Roma, Instituto Español de Historia Eclesiástica, 1963, pp. 57, 185, 206, 228.

78 SPERELLI, Alessandro: Il Vescovo, Roma, Gio Battista e Giuseppe Corvo Librari, 1655, tomo III, pp. 275276.

${ }^{79}$ LÓPEZ-GUADALUPE MUÑOZ, Miguel Luis: "De clero y fieles en la diócesis de Granada a través de las visitas pastorales de la segunda mitad del siglo XVIII”, Chronica Nova, no 23, 1996, p. 294.
} 
dividió el territorio. ${ }^{80}$ La visita del prelado parece, por tanto, inusual y limitada en el tiempo que tratamos, salvando la dedicación del arzobispo Llanes y Argüelles que la hizo completa y en varias ocasiones. En concreto, ya hemos referido su asistencia en 1784 y, por ello, la defensa jerezana tuvo que remontar su denuncia a pontificados anteriores. Sin embargo, Sevilla justifica la ausencia de sus titulares y aplaude la gestión de sus subordinados, aunque esto no fuera del gusto de Jerez, reseñando que la vicaría se había visitado hasta en dieciséis ocasiones entre 1726-1782 $2^{81}$ (quizás con una periodicidad trienal que no corresponde, al menos, con la documentación conservada) y que incluso un obispo auxiliar, Manuel Tercero, residió en ella entre $1740-1753 .{ }^{82}$ El pasto espiritual no debía faltar si los 230 eclesiásticos que contabiliza Martín Riego en $1759^{83}$ eran diligentes en sus funciones aunque esta cifra fuera sensiblemente menor que la aportada por la defensa hispalense: más de 240 sacerdotes, 150 confesores, 14 curas, cuatro tenientes y un vicario. ${ }^{84}$ Prueba de la suficiente presencia eclesiástica es la invariabilidad del número de curas tras la reforma beneficial de este siglo cuando incluso se doblaba el promedio diocesano de responsabilidad pastoral fijado en 383,2 vecinos $/$ cura. $^{85}$

Finalmente, los jerezanos criticaron la falta de interés de los arzobispos de Sevilla que no atendieron la necesidad material de sus seglares por desconocimiento. Situación que, por otra parte y según la defensa jerezana, no podía paliar el clero local, sumido en la miseria a pesar de los 120.000 ducados, regulados por quinquenio, que se obtenían por diezmos. ${ }^{86}$ Por ello, también solicitaron la administración de la materia decimal como veremos en el siguiente epígrafe. Aquí, podemos recordar algunas cifras generales donde la inspección sevillana recuerda la generosidad de la dignidad episcopal y de los capitulares. El documento que guía nuestra narración indica que el arzobispado contaba con 500 aranzadas de tierras de pan en el término de Jerez cuyo producto se repartió en su mayoría, el arzobispo Solís acostumbraba a dar doce fanegas de trigo al hospicio de niñas huérfanas, el arzobispo Delgado costeó numerosas dotes con 50-100 ducados y ayudó a otras tantas instituciones ${ }^{87}$ mientras el arzobispo Llanes contribuyó con más de 100.000 reales a la

\footnotetext{
${ }^{80}$ MARTÍN RIEGO, Manuel: “La visita pastoral de las parroquias”, Memoria Ecclesiae, no 14, 1999, p. 166.

81 ACS, Justicia, libro 120, f. 201.

82 ACS, Justicia, libro 120, f. 199.

83 MARTÍN RIEGO, Manuel: "El clero parroquial de la vicaría de Jerez en el siglo XVIII", Trivium: Revista de Estudios Humanisticos, $\mathrm{n}^{\circ}$ 6, 1994, pp. 178-179.

84 ACS, Justicia, libro 121, f. 31.

${ }^{85}$ LLANES Y ARGÜELLES, Alonso Marcos: Plan de erección..., op. cit.

86 ACS, Justicia, libro 120, ff. 148-153.

87 ACS, Justicia, libro 121, f. 31.
} 
compra de quina para hacer frente a las tercianas de 1786 y el cabildo catedral llevaba gastados $650.814,20$ reales para sufragar distintas necesidades en las dos últimas décadas. ${ }^{88}$

\section{La independencia económica de Jerez: ¿ruina de la iglesia de Sevilla?}

La suficiencia económica de una iglesia era esencial para su constitución como diócesis. No bastaba con tener las rentas necesarias para mantener el culto y el clero. Resultaba fundamental que no perjudicara el esplendor de la antigua sede como manifiesta Eloy de Morales en nombre del cabildo catedral de Sevilla:

Hasta a la Corona conviene que no se executen estas desmembraciones porque además de la importancia de que pueda mantener el decoro debido a su dignidad y a la alta gerarquía de la augusta familia de los príncipes que han solido honrar esta silla se interesa el estado de la subsistencia y socorro de los pueblos que muchos se verían desiertos si no se remediasen con estas rentas; perecerían sin duda en las calamidades de que con frecuencia se ven insultados de terremotos, langosta y otras epidemias, y con especialidad de las inundaciones del Río Guadalquivir que circula por todo este Arzobispado que ha sufrido desde tiempos mui antiguos innumerables estragos y convirtiéndose en ruinas en el presente muchos pueblos; por eso fue una de las máximas grandes del emperador Carlos Magno enriquecer las Yglesias y que sus prelados fuesen poderosos. ${ }^{89}$

Tanto la capacidad económica como la falta de perjuicio para Sevilla fueron defendidas por Jerez y objetadas por la dignidad que buscó desmontar todas las cifras aportadas por ésta en el intento de no perder al municipio más poblado y rico de la archidiócesis. El diezmo, principal fuente de ingresos de la iglesia hispalense, se repartía entre el arzobispo, el cabildo catedral, los beneficiados, el rey y las fábricas de las parroquias, en distinta proporción. El prelado reconoció la administración económica de los capitulares cediéndoles parte de sus frutos y las tercias reales se rediezmaban para atender las necesidades de los templos, cuando no se encontraron enajenadas. Salvo excepciones, los curas o beneficiados dobles del arzobispado no se beneficiaron de la materia decimal pues, en puridad, el prelado era el único cura de su jurisdicción y delegaba sus funciones pero no las rentas que, insuficientes, reclamaban una reforma económica como la que se llevó a cabo a fines del siglo XVIII. Por tanto, a los párrocos sólo les quedaba el consuelo de los derechos de estola, el pie de altar y, en algunos casos, las primicias. Aunque la práctica de recibir los primeros frutos era generalizada, hubo notables

\footnotetext{
88 ACS, Justicia, libro 120, f. 215.
}

${ }^{89}$ ACS, Justicia, libro 121, f. 233. 
excepciones, caso de las parroquias de Jerez. Al respecto, Martín Riego menciona que sólo se cobraban primicias en la iglesia colegial: apenas 408 reales/año del diezmo del abad y los canónigos a repartir entre los tres curas en el quinquenio de $1751-1755 .^{90}$ De igual modo, no faltaron matizaciones a la norma general de distribución del diezmo: iglesias priorales, señoríos de la dignidad, lugares de patronato, ciertas vicarías o monasterios tributaron de manera diferente. La colegiata jerezana del Salvador repartía sus diezmos entre el cabildo (2/3) y el abad y la capilla real de Granada (1/3) que cedían un noveno a la fábrica. ${ }^{91}$ Este noveno fue de 7.554 reales a mitad del siglo XVIII ${ }^{92}$ mientras el abad obtuvo 7.224 reales y los ocho canónigos 62.262 reales. ${ }^{93}$ No obstante, aún sin referencia concreta a la capilla real granadina y guiándonos por la citada regla de distribución, podemos deducir que las rentas decimales de la iglesia colegial eran inferiores a 100.000 reales, como aducía la defensa de Sevilla en el pleito (81.999 reales, sin aplicar el subsidio y el excusado) ${ }^{94}$ frente a los argumentos de los jerezanos que elevaron la cifra hasta los 168.000 reales al año. ${ }^{95}$ En cualquier caso, el escaso o nulo beneficio que obtuvo el arzobispado de los diezmos de la colegiata, hace pensar que las reticencias de los sevillanos se concentraron en la posible pérdida de las parroquias de la ciudad así como de aquellas que pudieron pertenecer al obispado asidonense, tal como reivindicó Cádiz. ${ }^{96}$ No en vano, la dezmería de la parroquia de San Miguel, unida quoad beneficia a la parroquia de Santiago, era una de las más preciadas de la archidiócesis como demuestran los importantes valores de los beneficios dotados en ella (contaba con una prestamera, la mejor dotada del arzobispado, de 55.000 reales agregada al cabildo catedral de Ceuta) ${ }^{97}$ o el tercio de fábrica que percibía $(35.142$ reales/año, a mitad del Setecientos) y que sólo fue secundado a lo lejos por la parroquia de San Miguel de Marchena (26.644), según la muestra ofrecida por Martín Riego. ${ }^{98}$ A nivel de vicaría, la participación de Jerez en el diezmo en especie (trigo y cebada) rozaba el 5\% del arzobispado en $1799^{99}$ y, aún así, se empeñaron en sostener que la independencia no mermaría la economía diocesana:

\footnotetext{
${ }^{90}$ MARTÍN RIEGO, Manuel: Diezmos eclesiásticos, rentas y gastos de la mesa arzobispal hispalense (17501800), Sevilla, Caja Rural, 1990, p. 62.

${ }^{91}$ Ibídem, pp. 28-29.

92 Ibidem, p. 47.

${ }^{93}$ Ibidem, p. 53.

${ }^{94}$ ACS, Justicia, libro 120, ff. 207-208.

95 ACS, Justicia, libro 121, f. 427.

96 ACS, Justicia, libro 120, f. 188.

${ }^{97}$ LLANES Y ARGÜELLES, Alonso Marcos: Plan de erección..., op. cit., pp. 61-62.

${ }^{98}$ MARTÍN RIEGO, Manuel: Diezmos eclesiásticos..., op. cit., pp. 46-47.

${ }^{99}$ Ibidem, p. 175.
} 
Los Prelados de Sevilla no necesitan a Xerez para que sea inmenso su pueblo. El número de almas que encierra la capital sola y el que por el resto de la diócesis ocupan las poblaciones más lucidas y ricas es casi infinito. Las rentas son tan proporcionadas a este grande número y a la fecundidad de un suelo, el más fértil en todo género de frutos. ${ }^{100}$

Con todo, la posición de la dignidad episcopal fue inamovible en un tiempo que tampoco era propicio para las concesiones. No fueron pocos los problemas que produjo el auto de 1777 que suprimía el beneficio prioral de Aracena para dotar competentemente los curatos de su vicaría a cambio de una compensación. ${ }^{101}$ Incluso, Galaroza buscó constituirse en cabeza de vicaría independiente en $1789 .^{102}$

Además, la cuestión económica no es ajena al pleito paralelo que se sostenía sobre la titularidad de la colegiata. Jerez defendió que la iglesia colegial era real e insigne correspondiéndole la administración de sus rentas. La representación de Felipe Santiago Gallo, en nombre de los capitulares sevillanos, desechaba ambos. Según éste, no se conocía bula de erección ni tampoco privilegio real denominándose en la documentación antigua como "iglesia maior de Sant Salvador" aunque reconoce la presencia de abad y calonges recibiendo diezmos desde $1265^{103}$, tal y como afirma la bibliografía actual. ${ }^{104}$ Dicha iglesia, por tanto y según el criterio de Santiago, sólo era la más antigua de la localidad y no cuestionaba su vinculación al ordinario que pone de relieve en los numerosos donativos de los prelados, fundamentalmente del cardenal Arias ${ }^{105}$, en la reconstrucción del templo. Aunque Santiago Escracho, en nombre de Jerez, no niega la participación de los arzobispos asegura que la obra nunca pudo concluirse sin los arbitrios y la liberalidad del papado y del rey. ${ }^{106}$

\footnotetext{
100 ACS, Justicia, libro 121, f. 427.

101 ARCHIVO HISTÓRICO NACIONAL (AHN), Consejos, legajo 15.406, exp. 14.

102 AGAS, Gobierno, Asuntos Despachados, legajo 70. Carta del Clero y Ayuntamiento de Galaroza al arzobispo Llanes. Galaroza, 2 de mayo de 1789.

103 ACS, Justicia, libro 121, f. 264.

104 GARCÍA ROMERO, Francisco Antonio y VEGA GEÁN, Eugenio José, “El cristianismo...”, art. cit., p. 25.

105 Invirtió 1.389.446 reales entre 1715 y 1722. ACS, Justicia, libro 120, ff. 212 vo.-213. Al respecto, José Luis Repetto alude al agradecimiento de los capitulares que ordenaron colocar las armas del eclesiástico en las puertas laterales del templo. REPETTO BETES, José Luis: La obra del templo de la Colegial de Jerez de la Frontera, Cádiz, Instituto de Estudios Gaditanos/Diputación de Cádiz, 1978, p. 87.

106 ACS, Justicia, libro 121, f. 411.
} 


\section{CONCLUSIONES}

En definitiva, la iniciativa de Jerez, civil antes que eclesiástica, aprovechó la coyuntura de la sede vacante por fallecimiento del arzobispo Delgado y la creación de otras iglesias para cumplir un anhelo de siglos. Para ello, desarrolló una operación de desgaste frente al arzobispado hispalense atacando primero con recursos históricos, donde no prescinde de mitos y falsificaciones, y después con los argumentos canónicos que exigía la extravagante Salvator Noster. Aunque sus averiguaciones no envidian las de otras iglesias honradas con la dignidad episcopal, nada pudieron hacer frente a la solvencia de la archidiócesis y la dilatación de la causa. Tampoco logró su propósito el obispado de Cádiz que intervino para sacar réditos de la defensa sevillana que, desde el comienzo, le adjudicó el traslado de la antigua sede asidonense. Por otra parte, la Corona siempre actuó desde la prudencia dando los pasos necesarios para no quebrantar la amistad de Sevilla, sede de gran capacidad económica, destino de diversos infantes y nobles, premio al mérito de destacados regalistas y consuelo de las innumerables deudas estatales. En el caso de Santander, la solicitud la firmaron los propios arzobispos de Burgos conscientes de la naturaleza abrupta de aquel territorio y las resistencias de su cabildo fueron vencidas a través de ciertas compensaciones. ${ }^{107}$ Jerez, en cambio, no tuvo más remedio que esperar dos siglos para llegar a la meta, un largo camino que remonta al medievo y que parcialmente hemos querido recordar en estas páginas.

107 LODOS, Francisco: "La creación del Obispado de Santander", Altamira: Revista del Centro de Estudios Montañeses, $\mathrm{n}^{\circ}$ 1-3, 1954-1955, pp. 109-242. 